\title{
Deri hastalıklarında kalsiyum kanal blokerlerinin kullanımı
}

\section{The use of calcium channel blockers in skin diseases}

Mualla Polat, Özge Uzun*

Abant İzzet Baysal Üniversitesi Tıp Fakültesi, Deri ve Zührevi Hastalıklar Anabilim Dalı ve *Farmakoloji Anabilim Dalı, Bolu, Türkiye

\section{Özet}

Kalsiyum kanal blokörleri hipertansiyon, anjina, periferik damar hastalıkları ve bazı aritmi durumları da dahil olmak üzere çoğunlukla kalp damar hastalıklarında kullanılan bir ilaç grubudur. Bu ilaçlar vasküler düz kas hücrelerinin ve fibroblastların proliferasyonunu ve büyümelerini baskılayabilir, kollajen, fibronektin, proteoglikan gibi ekstrasellüler matriks proteinlerinin sentezini de inhibe edebilirler. Bazı kalsiyum antagonistleri lenfositler üzerinde immünmodülatör veya disimmünregülatör etkiye sahiptir ve superoksit salıverilmesini veya nötrofillerin fagositik aktivasyonunu baskılayabilirler. Ayrıca mast hücre degranülasyonu ve trombosit agregasyonunu da bozabilir. Sözünü ettiğimiz bu özellikler dikkate alındığında, kalsiyum kanal blokerleri yaygın olarak kullanıldıkları kardiyovasküler hastalıkların tedavisi dışında dermatolojik hastalıkların tedavisinde de yer bulabilmektedirler. Sunduğumuz bu derlemede kalsiyum kanal blokerlerinin Raynaud fenomeni, pernio, kronik anal fissür, vulvodini, keloidler ve yanık izleri, kalsinozis kutis, leiomiyom gibi çeşitli dermatolojik hastalıkların tedavilerindeki kullanımları değerlendirilecektir. (Türkderm 2013; 47: 75-9)

Anahtar Kelimeler: Deri hastalıkları, kalsiyum kanal blokerleri

\section{Summary}

Calcium channel blockers are a group of drugs often used to treat cardiovascular diseases, such as hypertension, angina, peripheral vascular disorders and some arrhythmias. These drugs may suppress the growth and proliferation of vascular smooth muscle cells and fibroblasts, and inhibit the synthesis of extracellular-matrix proteins, such as collagen, fibronectin, proteoglycans. Some calcium channel blockers also have immunomodulatory or dysregulatory effects on lymphocytes and can suppress superoxide generation and phagocytic activity of neutrophils. Moreover, mast cell degranulation and platelet aggregation may also be impaired. On account of these properties, calcium channel blockers have also been used for the prevention and treatment of various dermatologic diseases. In this review, we evaluated the use of calcium channel blockers in various dermatologic diseases, such as Raynaud's phenomenon, chilblains, chronic anal fissures, vulvodynia, keloids and burn scars, calcinosis cutis, and leiomyoma. (Turkderm 2013; 47: 75-9)

Key Words: Skin disease, calcium channel blockers

\section{Giriş}

\section{Kalsiyum Kanal Blokerleri}

Kalsiyum kanallarını bloke eden moleküllerin damar düz kasları ve kalbin kasılmasını etkileyebileceği ilk kez 1960'lı yıllarda dikkati çektmiş̧ir'. O tarihten günümüze kalsiyum kanal blokerleri (KKB) özellikle hipertansiyon tedavisinde önemli ilaç gruplarından biri haline geldi. Günümüzde klinik kullanım için onay almış KKB değişik kimyasal yapılara sahip ilaçlardır. Bu açıdan üç alt grupta değerlendirilebilirler2:
1. Dihidropridinler (Nifedipin, Nikardipin, Nisoldipin, İsradipin, Felodipin ve Amlodipin)

2. Fenilalkilaminler (Verapamil, Gallopamil)

3. Benzodiazepinler (Diltiazem)

Bu moleküller kalsiyum kanallarının L-tipine yüksek afinite göstermektedir. L-tipi kalsiyum kanalları ise kalp kasında, damar düz kasında, bronşial, gastrointestinal, genitoüriner ve uterus düz kaslarında bulunmaktadır. Bunların dışında pankreas, hipofiz, adrenal bezi, tükrük bezleri, gastrik mukoza, lökositler, trombositler ve lakrimal doku gibi

Yazışma Adresi/Address for Correspondence: Dr. Mualla Polat, Abant İzzet Baysal Üniversitesi Tıp Fakültesi, Deri ve Zührevi Hastalıklar Anabilim Dalı, Bolu, Türkiye Gsm: +90 5053478952 E-posta: polatmualla@gmail.com Geliş Tarihi/Received: 07.04.2011 Kabul Tarihi/Accepted: 12.01.2012

Türkderm-Deri Hastalıkları ve Frengi Arșivi Dergisi, Galenos Yayınevi tarafından basılmıștır. Turkderm-Archives of the Turkish Dermatology and Venerology, published by Galenos Publishing. 
kontraktil olmayan yapılarda da L-tipi kalsiyum kanalları belirlenmiştir3 L-tipi kalsiyum kanalının, kanalı içeren ana alt biriminde (alfa-1alt birimi) yukarıda sözü edilen, yapıca farklı üç grup ilaç için bağlanma yerleri bulunmaktadır2. Alfa-1alt birimi, voltaj farklılıkları ve voltaja duyarlı kanal alt tipleri arasındaki farmakololjik duyarlıı̆ın belirlenmesinde de önemlidir4.

KKB'nin temel etkileri vazodilatasyon oluşturmalarıdır. Bununla birlikte yukarda sayılan ilaç grupları arasında farmakolojik etki profili açısından farklar bulunmaktadır. Dihidropridin türevleri vazoselektif ilaçlardır. Fenilalkilamin türevi olan verapamil ve benzodiazepin türevi olan diltiazemin ise kardiyak kasa selektivitesi daha fazladır. Ayrıca vazoselektif etki açısından bakıldığında damar yataklarının da ilaçların etkilerine bölgesel ve segmental farklar göterdiği anlaşılmışı²

KKB'nin vasküler düz kas hücreleri ve fibroblastlarda büyüme ve proliferasyonu inhibe edebildikleri gösterilmiştir. Ayrıca yine bazı KKB'nin kollagen, fibronektin, proteoglikan gibi ekstraselüler matriks proteinlerinin sentezini baskılayabilmekte olduğu anlaşılmıştır. Bu bulgular KKB'nin keloidler ve hipertrofik izlerin tedavisinde yararlı olabileceğini düşündürmektedir 5 . Diğer taraftan lenfositlerde kalsiyumun ve voltaj bağımlı kalsiyum kanallarının önemi üzerine yapılan araştırmalar immün sistemin kontrolünde de KKB'nin etkili olabileceğini akla getirmektedir6. Ilginç bir bulgu da mast hücrelerinin L-tipi kalsiyum kanalı sentezleyebildiğinin gösterilmiş olmasıdır7. Bu yolla sitozolik ve mitokondriyal kalsiyumun düzenlenmesi mast hücre aktivasyonu ile ilgili kimi süreçlerde KKB'nin etkili olabileceği sonucunu ortaya çıkarmaktadır. KKB'nden biri olan nikardipinin ekisi üzerine yapılan bir çalışmada ise bu ilacın antioksidan, anti-elastasik etkisi vurgulanarak, kimi enflamatuvar hastalıklarda yararlı olabileceği üzerinde durulmaktadır8. Bu açıdan örnekleri çoğaltmak olasıdır. Verapamil, gallopamid, diltiazem, nifedipin, felodipin, nimodipin ve nizoldipin de nötrofilleri etkileyebilmekte, süperoksit anyonu oluşumunu baskılayabilmektedir 5 .

KKB'nin antitrombositer etkileri ile yukarda sözünü edilen immünomodülatör etkileri Raynoud fenomeni, pernio ve kronik anal fissurlerin tedavisiyle ilişkilendirilebilmektedir ${ }^{5}$.

KKB'nin yan etkileri esas olarak vazodilatasyon, negatif inotrop ve dromotrop etkinin sonucu ortaya çıkmaktadır. Bunlar; baş ağrısı, baş dönmesi, al basması (Flushing) ve taşikardi gibi durumlardır. Ayrıca verapamil kullanan hastalarda konstipasyon, dihidropridin türevi KKB kullananlarda ise ayak bileği çevresinde ve topukta ödem ile gingiva hiperplazisi görülebilmektedir². Daha az görülen yan etkiler ise, yüz ve sırtta telenjiektazi, ışık duyarlılığı reaksiyonları, psoriasis alevlenmeleri, purpurik egzantemler, pemfigoid belirtiler, subakut kutanöz lupus eritematozus, jinekomasti, eritromelalji ve oral ülserlerdir 5 .

\section{KKB'nin dermatolojik endikasyonları}

Dermatolojide KKB Raynaud fenomeni ve pernio için ilk basamakta kullanılmaktadır. Bununla birlikte KKB'ü ilaçların kronik anal fissür, keloidler, yanık izleri, idiyopatik veya CREST (Calsinosis, Raynaud fenomeni, Esophageal dysmotility, Sclerodactyly, Telangiectasia) ile ilişkili kalsinozis kutis tedavisinde kullanımı konusunda klinik araştırmalar ve denemeler de sürmektedir. Ayrıca henüz deney hayvanlarında yapılan araştırmalar düzeyinde olmakla birlikte gelecekte deri flap nekrozunun önlenmesi ve tedavisi konusunda da KKB umut vermektedir. Aşağıda KKB burada sözünü ettiğimiz endikasyonlar ve yapılmış diğer çalışmalarla tartışılacaktır.
1. Raynaud Feomeni: Raynaud fenomeni parmaklarda solukluk, siyanoz, kızarıklık görülen, dijital arter ve arteriyollerin epizodik vazospazm atakları olarak tanımlanmaktadır ${ }^{9}$. En yaygın olarak soğuk maruziyeti ve/veya stres tarafından tetiklenmektedir. Raynaud fenomeni primer (Raynaud hastalığı) ve sekonder (Raynaud fenomeni) şeklinde sınıflandırılmaktadır. Raynaud hastalığı vazopazmın herhangi bir hastalıkla birlikteliğinin olmadığı, tek başına görüldüğü durumdur. Raynaud fenomeni ise diğer hastalıklarla, en sık da otoimmün hastalıklarla ilişkili vazospazm olarak tanımlanabilir9.

Dihidropiridin türevi KKB Raynaund fenomeni tedavisinde en çok kullanılan ilaç grubudur ${ }^{10}$. Bu ilaçlar içinde ise üzerinde en çok çalışma yapılan ilaç ise nifedipin olmuştur ${ }^{11}$. Nitekim KKB'lerinin primer Raynaund fenomeni tedavisindeki etkisinin 18 ayrı plasebo kontrollü çalışmayı kapsayan meta-analitik incelemesinde; bu grup ilaçların atak sıklığını ve hastalık şiddetini azalttığı çok net bir şekilde ortaya konmuştur ${ }^{12}$. Araştırmalar ilk tedavi seçeneği olan nifedipinin kısa etkili formu yerine devamlı salıveren formunun (DS) tercih edilmesi gerektiği göstermektedir. Bu farmasötik şekliyle olabildiğince düşük dozla tedaviye başlayıp, hastanın tolere edebilmesi durumuna göre, süreç içinde, etkin doza çıkılması önerilmektedir. Nifedipin dozu başlangıç için 10-20 mg/gün ve sonra da en yüksek doz da 80 mg/gün olarak belirtilmektedir 5 . Diğer taraftan Raynaud fenomeni tanısı konmuş 21 hastada yapılan bir araştırmada oda ısısındaki dijital hemodinamik değişiklikler incelendiğinde nifedipinin parmak kan akımında azalma ile sonuçlanan el perfüzyon basıncında akut düşme oluşturduğu tespit edilmiştir. Bu sonuç nifedipin kullanılırken dijital iskemi tehlikesi açısından dikkatli olunması gerektiğine dikkat çekmektedir ${ }^{13}$

Uzun etki süreli KKB'lerinden amlodipinin etkinliği primer Raynaud fenomeni olan hastalarda araştııılığında da hastalığın haftalık epizot sayısında ve şiddetinde tedavi boyuca belirgin şekilde düzelme tespit edilmiştir. Bu çalışmada önerilen günlük doz başlangıç için 2,5-5 mg sonrasında da 10 mg'a kadar çıkılabileceği yönündedir5. Bununla birlikte meme kanseri tanısı olan hastalarında hızlı gelişen Raynaud fenomeni nedeniyle $5 \mathrm{mg} /$ gün başlangıç dozu sonrasında $15 \mathrm{mg} /$ güne çıkarılan amlodipine yanıt alınamadığı da bildirilmektedir. Araştırıcılar bu durumda ancak meme kanserine yönelik kemoterapi sonrasında amlodipinle tedavinin başarı sağlayabileceğine dikkat çekmektedir ${ }^{14}$ Raynaud fenomeni tedavisinde kullanılması düşünülebilecek KKB'lerinden biri de diltiazemdir. Bu açıdan 16 hastada (7 ileri sistemik skleroz, 2 romatoid artrit, 1 sistemik lupus eritematozus ve 6 idiyopatik Raynaud fenomeni) diltiazemin etkisi değerlendirildiğinde plaseboya göre atak sıklığının ve şiddetinin istatistiksel açıdan anlamlı olmasa da azaldığı belirlenmiştir. Bu araştırmada hastalara iki hafta boyunca, günde üç kez 120 mg diltiazem verilmiştir. Çift kör, randomize, prospektif bir çalışma olarak planlanmış bu araştırmanın bir başka sonucu ise diltiazemin idiyopatik Raynaud fenomeni olan 6 hastada daha fazla etkili olduğudur15. Diltiazemin genellikle önerilen dozu primer Raynaund fenomeni için 60-120 mg olarak belirtilmekte, bu dozun günde 2 kez veya 3 kez verilmesi gerektiği etkinliğin başlaması içinse en az 2 hafta beklenmesi gerektiğinden söz edilmektedir. Ayrıca diltiazemin devamlı salıveren formu için de doz aralığı 120-300 mg/gün olarak bildirilmektedir 5 . Sonuç olarak; KKB'nden nifedipinin bugünkü bilgilerimize göre Raynaud fenomeni tedavisinde ilk seçenek olduğu anlaşılmaktadır. Diğer vazoselektif KKB (felodipin, nizoldipin, isradipin ve nikardipin) ile yapılmış araştırmalar da göstermektedir ki uygun doz ve kullanım süresi ile tedavide başarı oranı artmaktadır. 
2. Pernio: Pernio, soğuğa maruziyet sonrası oluşan lokalize eritem ve şişliktir. Periferal dolaşım bozukluğu olan hastalarda hafif soğukta dahi oluşabilmektedir. Genellikle el-ayak parmakları, alt ekstremite distalleri, burun ve kulaklarda ortaya çıkan duyarlılık, kaşıntı, kırmızı-morumsu eritem ile ortaya çıkan bir durum olarak tanımlanabilir16. Tedavide nifedipinin olumlu etkilerini gösteren çok sayıda çalışma bulunmaktadır. Örneğin 40-60 mg/gün dozunda nifedipin kullanıldığında pernio tanısı konmuş hastalarda lezyonların kaybolması için geçen zamanın anlamlı derecede kısaldığı gösterilmiştir. Aynı hasta grubunda nifedipin, ağrı ve lezyonun irritasyonunu da azaltmaktadır ${ }^{17}$. Pernioda nifedipin ve diltiazemin etkinliği arasında bir karşılaştırma yapıılığında ise diltiazemin nifedipinden daha az etkili olduğu sonucu ortaya çıkmıştır ${ }^{18}$.

\section{KKB'nin diğer dermatolojik hastalıklarda kullanımlarına ilişkin araştırmalar}

1. Kronik anal fissürler: Kronik anal fissür, dentat çizgiden anal vergeye uzanan anal kanal mukozasının longitudinal veya armut şeklindeki defekti olarak tanımlanmaktadır ${ }^{19}$. Tipik bir fissürde en sık gözlenen bulgu internal anal sfinkterin spazmına bağlı oluşan ve sfinkter iskemisi sonucu gelişen çok şiddetli ağrıdır. Spazmın rahatlatılması, ağrının hafiflemesi ve fissürün iyileşmesiyle olasıdır. Sfinkter kontraksiyonu ise sitoplazmik kalsiyum artışı ile ilişkilendirilmektedir5,19. Bu bilgilerden yola çıkarak anal fissürün en iyi tedavisinin normal sfinkter fonksiyonunda kalıcı bir hasar oluşturmadan, anal kanal dinlenme basıncını geçici olarak azaltmayı indüklerken eş zamanlı olarak fissürde iyileşmeyi sağlayacak anal mukozal kan akımını düzeltmek olduğu sonucuna varmak mümkündür. Bu nedenle de bazı KKB (nifedipin, diltiazem, lasidipin) kronik anal fissürlerin konservatif tedavisinde kullanılabilir.

Anal fissürlerin tedavisinde Jonas-Obichere ve arkadaşlarının yaptığı bir çalışma bu açıdan ilginçtir20. Bu araştırmada internal anal sfikter basıncının azaltılmasında nitrik oksit ve KKB etkisi izole koyun internal anal sfinkterinde değerlendirilmiştir. Sonuçta da sodyum nitroprussid, gliseril trinitrat, nikorandil, nifedipin, diltiazem ve verapamil solüsyonlarının miyojenik tonüsde sırasıyla $\% 100, \% 78, \% 85, \% 78,2$, $\% 83,8$, \%66,4 oranında inhibisyon oluşturduğu belirlenmiştir. Bir başka araştırmada ise kronik anal fissürün cerrahi tedavisine bağlı ortaya çıkabilecek komplikasyonların çokluğu nedeniyle alternatif tedavi yöntemleri olarak nifedipin, gliseril trinitrat ve botulinum toksini tedavilerinin etkinliğini araştırımıştır. Bu üç tedavi seçeneğinin her birinde de cerrahi tedaviye alternatif teşkil edebilecek düzeyde olumlu sonuçlar alındığı bildirilmiştir21. Anal fissür tedavisinde nifedipinin etkin bir tedavi seçeneği olduğuna dair literatürde başka çalışmalar da bulunmaktadır21-26.

Kronik anal fissür tedavisinde oral (60 mg $2 \times 1,8$ hafta süreyle) ve topikal uygulama ile diltiazemin etkinliği de çalışılmıştır. Araştırıcılar topikal tedavi ile daha az yan etki ve daha yüksek sağaltım başarısı elde ettiklerini bildirmişlerdir24. Bu sonucu destekleyen başka araştırmalarda da topikal diltiazem \%2'lik jelinin günde iki kez, 8 haftalık kullanımı ile iyileşme oranının \%67-86 arasında değiştiği ayrıca ilacı uygulama sıklı̆ının günde üçe çıkmasının ek bir iyileşme sağlamadığı ortaya çıkmıştır25,26. Tedavide etkin bir başarı da sıcak oturma banyosu ve gaita yumuşatıcıları ile birlikte oral lasidipin uygulaması ile elde edilmiştir27. Sonuç olarak KKB anal fissürlerin tedavisinde etkin bir tedavi seçeneği olarak karşımıza çıkmaktadır.
2. Vulvodini: Vulvodini, tanısı sıklıkla atlanan ve tedavisi oldukça zor olan bir hastalıktır. Semptomları açıklayacak objektif klinik ve laboratuvar bulgular olmaksızın en az 3 aydır varolan vulvadaki ağı ve/veya kronik yanmayı tanımlamak için kullanılmaktadır. Prevalansı \%1,3-28 arasında değişmektedir. Fizyopatolojisi henüz net olarak açıklanamamıştır. Vulvodininin başlıca belirtisi, genital bölgedeki ağrıdır. Beraberinde yanma, kaşıntı ve disparoni de olabilir. Vulvodini artmış depresif semptomlarla birlikte olabilir. Durumu değerlendirmek için jinekolog, dermatolog, psikolog, psikiyatrist, fizik tedavi uzmanı ve ağıı bilim dalını kapsayan multidisipliner bir yaklaşım gerekir28.

Vulvodini ve kronik anal fissür arasındaki musküler hipertonisite ve inflamatuvar infiltrat benzerliğinden yola çıkarak, kronik anal fissür tedavisinde etkili olduğu bildirilen KKB'nin vulvodini tedavisinde de etkili olabileceği düşünülmüştür28. Ancak bu amaçla planlanan plasebo konrollü araştırmada \%2 ve \%4'lük nifedipinin (krem formunda günde 4 kez, 6 hafta süreyle) pek de fayda sağlayamadığı anlaşılmıştır28.

3. Keloidler ve yanık izleri: Keloid yaralanmayı takiben veya bazen kendiliğinden oluşan kontrolsüz fibröz doku proliferasyonu olarak tanımlanabilir29. Kollajenaz aktivitesinde artış ve lokal olarak aşırı Tip 1 kollajen sentezi artışılla karakterizedir. Aynı tablonun parçaları olarak kabul edilen iki hastalıktan keloid, hipertrofik skardan farklı olarak yaralanma bölgesi dışına da yayılmaktadır29. Ekstraselüler matriks proteinlerinin aşırı üretimi ve depolanmalarıyla tanımlanabilecek bu tablolarda hücresel kalsiyum iyonunun metabolizmasının rol oynayabileceği belirten araştırmalar bulunmaktadır30,31. Nitekim amlodipin, felodipin, manidipin, diltiazem ve verapamil gibi beş kalsiyum antagonisti ile in vitro koşullarda yapılan bir çalışmada, KKB'lerinin ekstrasellüler matrikste kollajen depolanmasını önemli derecede azalttığı ve farklı kolajenlerin (Tip 1-3-4) ekspresyonunu inhibe ettiği anlaşılmıştır31. Buna ek olarak araştırıcılar KKB'lerin kolajenaz 4'ün proteolitik aktivitesini spesifik olarak arttırdığını da vurgulamışlardır. Bu bilgilere dayanılarak verapamil keloid ve yanık izlerinin rekurrensini önlemek ve tedavi etmek amacıyla kullanılmışır 32 . Sonuçta keloidi stabilize etmek amacıyla verapamil kullanılması topikal steroidlere göre çok daha zayıf bir etki göstermiş, ancak verapamil keloidin cerrahi olarak eksizyonunun ardından 7., 14. ve 28. günlerde ve 2. ayda 2,5 mg/ml (lezyonun genişliğine göre 0,5-2 ml arasında değişebilen dozlarda) olarak topikal silikon ile kombine edildiğinde tedavi başarısı \%54'e ulaşmıştır. Buna ek olarak 18 ay boyunca rekürrens olmadığı anlaşılmıştır 32 . Verapamilin keloid üzerindeki etkisinin prokollojenaz sentezini stimüle etmesinin dışında fibroblast kültürlerinde IL-6'nın ve Vasküler Endotelyal Büyüme Faktörünün üretiminin inhibe edilmesi ile ilişkili olduğu gösterilmiştir33.

4. Kalsinozis kutis: Kalsinozis kutis, deride kalsiyum birikimini tanımlamak için kullanılan bir durumdur. Deride biriken kalsiyum, amorf çözünmeyen kalsiyum tuzları şeklindedir34. Oluşum mekanizmalarına göre; distrofik, metastatik, iyatrojenik ve idiyopatik olarak dört grupta incelenmektedir. Distrofik kalsifikasyon genellikle inflamasyonlu bölgeye kalsiyum tuzlarının çökmesi sonucu oluşmaktadır. Kollajen doku hastalıkları en önemli sebeplerinden biri olarak görülmektedir. Deride kalsiyum birikimine neden olan hastalıklar; CREST sendromu, sistemik lupus eritematozus, skleroderma olarak sıralanabilir34.

Vayssairat ve arkadaşları sistemik skleroz tanısı ile takip ettikleri 47 hastanın 23'ünde kalsinozis kutis tespit ettiklerini, bu hastalarda duruma eşlik eden Raynaud fenomenide olduğu için diltiazem $60 \mathrm{mg}$ 
3x1 tedavisi başladıklarını ve tedavi sonrası 3 hastada hafif gerileme olduğunu bildirmişlerdir35. Diltiazem kullanımının etkisiz olmadığını ancak kendilerinden önce çok etkili olduğu bildirilen çalışmalarda ilaç dozunun daha yüksek olduğunu belirtmişlerdir. Vakalar düzeyinde yapılan bildiriler de daha çok kalsinozis kutis tedavisinde diltiazemin etkisinin olumlu olduğu yönündedir36,37. Literatürdeki bir başka önemli bulgu da şiddetli kalsinozisi olan juvenil dermatomiyozisli 12 yaşındaki erkek bir hastanın prednizolon ( $50 \mathrm{mg} / \mathrm{gün}$ ) tedavisi yanında verilen diltiazem (30 mg/gün) tedavisi ile beş ay gibi kısa bir sürede lezyon ve kalsifikasyonlarında hızla gerileme belirlenmesidir37. Sonuçta bu terapötik etki KKB'nin intrasellüler kalsiyum konsantrasyonunda düşme sağlaması ve bunun da kristal formasyonunun oluşumunu azalttığı şeklinde yorumlanabilmektedir 5 .

5. Kutanöz leiomiyom: Kutanöz leiomiyom, düz kasın selim tümörü olan pilar leiomyom deride M. erektör piliden köken almaktadır. Genellikle genç yaşta ortaya çıkmakta, en sık ekstremitelerin ekstensör yüzleri, gövde, yüzün yan kısmı ve boyunda yerleşmektedir39. Kutanöz leiomiyom, birkaç mm ile bir santimetre arasında değişen çaplarda, kırmızımsı kahverengi, infiltre, kabarık, dağınık veya küme oluşturan papülonodüler lezyonlar şeklinde görülmektedir. Histopatolojik olarak dermiste düz kas demetlerinin görülmesi tipiktir. Selim bir lezyon olup leiomiyosarkoma dönüşüm söz konusu değildir39. Dokunmakla oluşan ağrının yanı sıra kendiliğinden oluşan ağrı atakları da tanıda yardımcı olan semptomatik özelliklerdir. Tedavide ağrılı lezyonlarda cerrahi de uygulanabilmektedir. Bununla birlikte, geniş alanda çok sayıda lezyonun olduğu hastalarda başarılı bir şekilde total eksizyon güç olduğundan, KKB'leri, alfa adrenerjik blokerler, nitrogliserin, fenoksibenzamin kullanımı önerilmektedir39. Nitekim ağrılı leiomyomları olan vakalarda nifedipinin günde 3 kere $10 \mathrm{mg}$ dozunda ve 3 ay süreyle tek başına kullanımı tercih edildiğinde ağrının önemli oranda azaldığı belirlenmiştir40.

6. Perioküler kırışıklık tedavisinde: Perioküler kırısıklık mimik kaslarının kronik kontraksiyonu sonucunda oluşmaktadır. Innocenti ve arkadaşları kas hücrelerindeki kalsiyum kanal blokajı oluşturarak kronik kontraksiyonların önüne geçilebileceğini, böylece kırışıkların derinliğinde azalma sağlanabilecekleri hipotezi ile topikal \%0,5 nifedipin kremi 64 kadın hastada 90 gün süreyle kullanmışlardır. Bulgular, perioküler kırısıklıkların derinliğini azaltmada nifedipin uygulamasının etkili olduğu yönündedir41

\section{Deri flap nekrozunun önlenmesi ve tedavisinde deneysel çalışmalar}

Mikrovasküler cerrahide perioperatif veya postoperatif olarak ortaya çıkan arteriyel vazokonstriksiyon sıklıkla karşılaşılan bir durum olarak bilinmektedir. Böyle bir durumda kan akımında yetersizlik ortaya çıkması, deri flapi gibi revaskülarize olması gereken dokuların canlıı̆ını riske atmaktadır42,43. Bu nedenle; vazokonstriksiyonun önlenmesi için KKB'leri ve antitrombositer etkisi olan ilaçlar oluşturulan hayvan modellerinde kullanılmış ve kan akımını düzenledikleri gösterilmiştir41-44. Bunun bir örneği sıçan karın duvarına yapılan deri flaplarinde verapamil uygulaması sonucu daha az nekroz geliştiğinin gösterilmiş olmasıdır 42 . Benzer şekilde fare ve tavşanlarda oluşturulan deneysel modellerde de deri flap nekrozunun önlenmesi için nifedipin, nimodipin, nitrendipin ve diltiazemin topikal (perilezyonel) veya sistemik uygulamaları yapılmış ve nekroz oluşumunda azalma belirlenmiştir43. Son zamanlarda yapılan bir çalışmada ise nikotinin fare derisinde oluşturmuş olduğu etkileri verapamil ve nifedipinin azalttığı ve flap sağ kalımına istatistiksel olarak anlamlı bir şekilde katkı sağladığı gösterilmiştir. Bu durum KKB'nin flap ameliyatı gerektiren aktif sigara içenlerde ameliyatlarda komplikasyon riskini azaltabileceğini düşündürmektedir 44 .

\section{Sonuç}

Yapılan araştırmalar ve deneysel çalışmalar bazı dermatolojik hastalıklarda ilk tercih olarak kullanılan KKB'nin yakın zamanda daha geniş bir kullanım alanı bulacağını göstermektedir. Bu açıdan henüz çok erken olmakla birlikte, deneysel çalışmalardan elde edilen bilgiler KKB'nin özellikle flap cerrahisi başarısı açısından umut verici olduğunu düşündürmektedir.

\section{Kaynaklar}

1. Fleckenstein A: History of calcium antagonists. Circ Res 1983;52:13-6.

2. Kayaalp O: Rasyonel tedavi yönünden tıbbi farmakoloji.12. Baskı. Ankara, Pelikan Yayıncılık, 2009;368-72.

3. Abernethy DR, Schwartz JB: Calcium-antagonist drugs. N Engl J Med 1999;341:1447-57.

4. Flynn JT, Pasko DA: Calcium channel blockers: pharmacology and place in therapy of pediatric hypertension. Pediatr Nephrol 2000;15:302-16.

5. Palamaras I, Kyriakis K: Calcium antagonists in dermatology: a review of the evidence and research-based studies. Dermatol Online J 2005;11:8.

6. Triggle DJ: Calcium channel antagonists: clinical uses-past, present and future. Biochem Pharmacol 2007;74:1-9.

7. Yoshimaru T, Suzuki Y, Inoue T, Ra C: L-type Ca2+ channels in mast cells: activation by membrane depolarization and distinct roles in regulating mediator release from store-operated $\mathrm{Ca} 2+$ channels. Mol Immunol 2009;46:1267-77.

8. Kouoh F, Gressier B, Dine T, et al: Antioxidant effects and anti-elastase activity of the calcium antagonist nicardipine on activated human and rabbit neutrophils-a potential antiatherosclerotic property of calcium antagonists? Cardiovasc Drugs Ther 2002;16:515-20.

9. Baykal C: Dermatoloji atlası. 2. Baskı. İstanbul, Argos Yayıncılık, 2004;288-9.

10. Bakst R, Merola JF, Franks AG Jr, Sanchez M: Raynaud's phenomenon: pathogenesis and management. J Am Acad Dermatol 2008;59:633-53.

11. Levien TL: Advances in the treatment of Raynaud's phenomenon. Vasc Health Risk Manag 2010;6:167-77.

12. Thompson AE, Pope JE: Calcium channel blockers for primary Raynaud's phenomenon: a meta-analysis. Rheumatology (Oxford) 2005;44:145-50.

13. Wise RA, Malamet R, Wigley FM: Acute effects of nifedipine on digital blood flow in human subjects with Raynaud's phenomenon: a double blind placebo controlled trial. J Rheumatol 1987;14:278-83.

14. Allen D, Robinson D, Mittoo S: Paraneoplastic Raynaud's phenomenon in a breast cancer survivor. Rheumatol Int 2010;30:789-92.

15. Kahan A, Amor B, Menkes CJ: A randomised double-blind trial of diltiazem in the treatment of Raynaud's phenomenon. Ann Rheum Dis 1985;44:30-3.

16. Baykal C: Dermatoloji atlası. 2. Baskı. İstanbul, Argos Yayıncılık, 2004;306-7.

17. Rustin MH, Newton JA, Smith NP, Dowd PM: The treatment of chilblains with nifedipine: the results of a pilot study, a double-blind placebo-controlled randomized study and a long-term open trial. $\mathrm{Br} J$ Dermatol 1989;120:267-75

18. Patra AK, Das AL, Ramadasan P: Diltiazem vs. nifedipine in chilblains: a clinical trial. Indian J Dermatol Venereol Leprol 2003;69:209-11.

19. Ersan $Y$, Yavuz N, Çiçek $Y$, et al: Surgical treatment in cases of chronic anal fissure. Cerrahpaşa J Med 2005;36:213-7.

20. Jonas-Obichere $M$, Scholefield JH, Acheson A, et al: Comparison of the effects of nitric oxide donors and calcium channel blockers on the intrinsic myogenic tone of sheep isolated internal anal sphincter. $\mathrm{Br} J$ Surg 2005;92:1263-9. 
21. Uluutku H, Akın ML, Erenoğlu C, et al: Kronik anal fissür tedavisinde nifedipin, gliseril trinitrat ve botilinum toksinin etkinliğinin değerlendirilmesi. Ulusal Cerrahi Dergisi 2001;17:343-50.

22. Ağaoğlu N, Cengiz S, Arslan MK, Türkyilmaz S: Oral nifedipine in the treatment of chronic anal fissure. Dig Surg 2003;20:452-6.

23. Perrotti P, Bove A, Antropoli C, et al: Topical nifedipine with lidocaine ointment vs. active control for treatment of chronic anal fissure: results of a prospective, randomized, double-blind study. Dis Colon Rectum 2002;45:1468-75.

24. Jonas M, Neal KR, Abercrombie JF, Scholefield JH et al: A randomized trial of oral vs. topical diltiazem for chronic anal fissures. Dis Colon Rectum 2001;44:1074-8

25. Knight JS, Birks M, Farouk R: Topical diltiazem ointment in the treatment of chronic anal fissure. Br J Surg 2001;88:553-6.

26. Griffin N, Acheson AG, Jonas M, Scholefield JH: The role of topical diltiazem in the treatment of chronic anal fissures that have failed glyceryl trinitrate therapy. Colorectal Dis 2002:4:430-5.

27. Ansaloni $L$, Bernabè $A$, Ghetti $R$, et al: Oral lacidipine in the treatment of anal fissure. Tech Coloproctol 2002;6:79-82.

28. Bornstein J, Tuma R, Farajun Y, Azran A, Zarfati D: Topical nifedipine for the treatment of localized provoked vulvodynia: a placebo-controlled study. J Pain 2010;11:1403-9.

29. Baykal C: Dermatoloji atlası. 2. Baskı. İstanbul, Argos Yayıncılık, 2004;1603-4.

30. Lee RC, Ping JA: Calcium antagonists retard extracellular matrix production in connective tissue equivalent. J Surg Res 1990;49:463-6.

31. Roth M, Eickelberg O, Kohler E, Erne P, Block LH. Ca2+ channel blockers modulate metabolism of collagens within the extracellular matrix. Proc Natl Acad Sci USA 1996;93:5478-82.

32. D'Andrea F, Brongo S, Ferraro G, Baroni A. Prevention and treatment of keloids with intralesional verapamil. Dermatology 2002;204:60-2.
33. Giugliano G, Pasquali D, Notaro A, et al: Verapamil inhibits interleukin-6 and vascular endothelial growth factor production in primary cultures of keloid fibroblasts. Br J Plast Surg 2003;56:804-9.

34. Baykal C: Dermatoloji atlası. 2. Baskı. İstanbul, Argos Yayınclık, 2004; 376-77.

35. Vayssairat M, Hidouche D, Abdoucheli-Baudot N, Gaitz JP: Clinical significance of subcutaneous calcinosis in patients with systemic sclerosis. Does diltiazem induce its regression? Ann Rheum Dis 1998;57:252-4

36. Ichiki Y, Akiyama T, Shimozawa N, et al: An extremely severe case of cutaneous calcinosis with juvenile dermatomyositis, and successful treatment with diltiazem. Br J Dermatol 2001;144:894-7

37. Abdallah-Lotf $M$, Grasland $A$, Vinceneux $P$, Sigal-Grinberg $M$ : Regression of cutis calcinosis with diltiazem in adult dermatomyositis. Eur J Dermato 2005; 15:102-4

38. Jiang $X, Y i$ Q, Liu D, Wang S, Li L: A case of juvenile dermatomyositis with severe calcinosis and successful treatment with prednisone and diltiazem. Int J Dermatol 2011:50:74-7.

39. Baykal C: Dermatoloji atlası. 2. Baskı. İstanbul, Argos Yayıncılık, 2004;545-6

40. George S, Pulimood S, Jacob M, Chandi SM: Pain Pain in multiple leiomyomas alleviated by nifedipine. Pain 1997:73:101-2.

41. Innocenti M, Ramoni S, Doria C, et al: Treatment of periocular wrinkles with topical nifedipine. J Dermatolog Treat 2010;21:282-5.

42. Komorowska-Timek E, Chen SG, Zhang $F$ et al: Prolonged perivascular use of verapamil or lidocaine decreases skin flap necrosis. Ann Plast Surg 1999:43:283-8.

43. Kawabata H, Knight KR, Coe SA, Angus JA, O'Brien BM: Experience with calcium antagonists nitrendipine, diltiazem, and verapamil and beta 2-agonist salbutamol in salvaging ischemic skin flaps in rabbits. Microsurgery 1991;12:160-3

44. Rinker B, Fink BF, Barry NG, Fife JA, Milan ME: The effect of calcium channel blockers on smoking-induced skin flap necrosis. Plast Reconstr Surg 2010;125:866-71 